\title{
Diurnal Temperature Range Compression Hastens Berry Development and Modifies Flavonoid Partitioning in Grapes
}

\author{
Seth D. Cohen, ${ }^{1}$ Julie M. Tarara, ${ }^{2}$ and James A. Kennedy ${ }^{1,3 *}$
}

\begin{abstract}
Temperatures during the day and night are known to influence grape berry metabolism and resulting composition. In this study, the flavonoid composition of field-grown Vitis vinifera L. cv. Merlot berries was investigated as a function of diurnal temperature range (DTR). The DTR was compressed by cooling berries during the day and heating them at night. Before veraison, there were minor differences in proanthocyanidin (PA) composition in the skins and seeds due to temperature treatments, most notably a decrease in gallate-esterification of seed flavan3-ols with compressed DTR. Compressing the DTR significantly hastened berry development and the inception of veraison. Treatments imposed after veraison had minimal impact on skin and seed PAs; however, compressed DTRs favored the partitioning of anthocyanins and flavonols toward B-ring di-substitution. Compressing the DTR of grape berries had a consistent effect on berry development and partitioning of flavonoid metabolites while total flavonoid content was not significantly altered.
\end{abstract}

Key words: Vitis vinifera, tannin, anthocyanin, flavonol, phenolic, climate

The successful cultivation of winegrapes (Vitis vinifera L.) involves matching cultivar to geography and climate. While all elements of climate should be considered, temperaturebased predictions are most common. This is illustrated in the degree day classification system for grape cultivation in the United States (Amerine and Winkler 1944). The basis for this system is the general temperature requirement for fruit to reach acceptable maturity, defined primarily by sugar concentration. Differences in temperature ranges can be attributed to variations in latitude, topography, and the proximity to large bodies of water, which moderate nearby land temperatures due to the high heat capacity of water, as evident in annual and daily temperature fluctuations or the diurnal temperature range (DTR).

The response of primary metabolites to temperature has been established. Generally, higher temperatures during fruit ripening lead to an increase in the rates of sugar accumulation and organic acid degradation while lower temperatures can lead to a reduction in the rates of sugar accumulation and

\footnotetext{
${ }^{1}$ Department of Food Science and Technology, Oregon State University, Corvallis, OR 97331; ${ }^{2}$ United States Department of Agriculture-Agricultural Research Service, Horticultural Crops Research Unit, 24106 N. Bunn Rd., Prosser, WA 99350; and (currently) ${ }^{3}$ Department of Viticulture and Enology, California State University, 2360 East Barstow Ave., Fresno, CA 93740.

*Corresponding author (email: jakennedy@csufresno.edu; fax: 559 278-4795) Acknowledgments: This work was funded by the American Vineyard Foundation, the Viticulture Consortium-West, and USDA-ARS CRIS no. 535821000-00D. Mention of trade names or commercial products in this article is solely for the purpose of providing specific information and does not imply recommendation or endorsement by the USDA.

The authors thank John Ferguson, USDA-ARS, for maintaining the field equipment.

Manuscript submitted Feb 2011, revised May 2011, Sept 2011, accepted Oct 2011

Copyright $(2012$ by the American Society for Enology and Viticulture. All rights reserved.

doi: 10.5344/ajev.2011.11015
}

organic acid degradation (Kliewer 1964, 1965, Buttrose et al. 1971, Kliewer and Torres 1972). While the concentration of sugars and acids can be adjusted to reach a desired sweetness, alcohol potential, and acidity during wine processing, the concentrations of secondary metabolites are more difficult to manipulate.

Proanthocyanidins (PAs), or flavan-3-ol polymers, are responsible for wine astringency; they accumulate in grape skins and seeds early in development before a lag period in berry growth, after which there is a decline in the rate of accumulation (Downey et al. 2003a). The inception of ripening (veraison) is characterized by rapid accumulation of skin anthocyanins in red grapes, the source of color in red wine (Pirie and Mullins 1980). Flavonols, which are thought to provide some stability to both PAs and anthocyanins, accumulate in the skin early in development and continue through berry ripening (Boulton 2001, Downey et al. 2003b). While flavonol contents increase in response to UV exposure, temperature does not appear to have an influence (Spayd et al. 2002).

Previous research has demonstrated effects of both high and low temperatures on anthocyanin accumulation. Inhibition of anthocyanin development was reported at higher temperatures (e.g., $35^{\circ} \mathrm{C}$ ), while at moderate day temperatures (e.g., $25^{\circ} \mathrm{C}$ ) anthocyanin accumulation was inversely related to DTR (Kliewer and Torres 1972, Kliewer 1977). A hastening of berry coloration is associated with increased preveraison night temperature, while similar temperatures during ripening can reduce anthocyanin accumulation (Kobayashi et al. 1967). Subsequent work has confirmed reduced anthocyanin accumulation at higher day $\left(>30^{\circ} \mathrm{C}\right)$ and night $\left(30^{\circ} \mathrm{C}\right.$ vs. $\left.15^{\circ} \mathrm{C}\right)$ temperature and temperature-related partitioning (Kliewer 1977, Mori et al. 2005, Yamane et al. 2006, Tarara et al. 2008). Heat-mediated reduction of anthocyanin accumulation was related to reductions in gene transcripts and enzyme activities as well as degradation of existing anthocyanins (Mori et al. 2005, 2007, Yamane et al. 2006). 
Most research regarding the accumulation of PAs has focused on the impact of solar radiation. For example, exposure to solar radiation, and in some instances UV specifically, resulted in increased PA accumulation in several cultivars of $V$. vinifera (Downey et al. 2004, Cortell and Kennedy 2006, Koyama and Goto-Yamamoto 2008). Little work has been done to decouple the effects of light exposure and temperature. It is documented that the surface temperature of exposed berries may exceed air temperature by as much as $14^{\circ} \mathrm{C}$, bringing into question the effects attributed to light exposure versus temperature alone (Smart and Sinclair 1976, Tarara et al. 2000).

The objective of this research was to determine the effects of compressing the DTR on flavonoid accumulation in $V$. vinifera cv. Merlot berries grown under field conditions. The first year of experimental data (2006) was published previously, specifically to describe an analytical method for profiling PA metabolism and accumulation in grape berries (Cohen et al. 2008). Relevant data from 2006 are included here to provide reference and statistical analysis for three years of a replicated field experiment focused on the DTR. Data presented here demonstrate the effects of DTR compression on PAs from both seeds and skins and on anthocyanins and flavonols from skins. Experiments were conducted in a mature vineyard from fruit set to veraison and again from veraison to fruit maturity to coincide with the active periods of accumulation of the different classes of metabolites across three consecutive experimental seasons. Berry temperatures were manipulated such that the natural diurnal pattern of temperature in the field was conserved.

\section{Materials and Methods}

Field procedure. The three-year study spanned 2006 to 2008 at the Irrigated Agriculture Research and Extension Center near Prosser, WA $\left(46.30^{\circ} \mathrm{N} ; 119.75^{\circ} \mathrm{W}\right)$. Own-rooted Merlot vines (planted in 1999) were in rows oriented northsouth, with $2.3 \mathrm{~m}$ between rows and $1.8 \mathrm{~m}$ between vines within a row. Vines were trained to a bilateral cordon at 1.2 $\mathrm{m}$ aboveground and winter-pruned annually to 2-bud spurs. Vines were managed according to standard commercial practice for the district. Experimental clusters were oriented on the east aspect of the vine and were exposed uniformly to irradiance $\left(\mathrm{R}_{\mathrm{s}}\right)$ by tucking shoots and leaves behind a catch wire at $1.5 \mathrm{~m}$ aboveground. Treatments were applied to individual clusters, and each cluster was treated as a replicate $(\mathrm{n}=4)$.

Three temperature-control treatments were applied: (1) no temperature control (ambient); (2) convective control (blow); and (3) compressed DTR (damp). Treatments were applied based on stages of berry development using the modified $\mathrm{E}-\mathrm{L}$ system (Coombe 1995): (1) between stages 27-28 ( 2 to $4 \mathrm{~mm}$ berry diam) and stages 34-35 (veraison; onset of ripening), termed Period I, and (2) between stages 34-35 and commercial maturity, termed Period II. Commercial maturity was defined as berry soluble solids $\geq 22$ Brix in a random sample of 100 berries collected from untreated clusters on the experimental vines. Fruit temperatures were controlled in both
Periods I and II in 2006 and 2007, while observations in 2008 were limited to Period I.

There was no modification of fruit microclimate for ambient clusters, except to maintain uniform exposure to $R_{s}$. Damp was accomplished by forced convection without the use of enclosures (Tarara et al. 2000) to minimize changes in radiation and humidity around the fruit. Chilled air was delivered during the day and heated air during the night. The average temperature of untreated clusters $(n=4)$ was used as a reference from which air was delivered to damp clusters as needed, at 5-sec intervals, to maintain an offset from ambient clusters of $-8^{\circ} \mathrm{C}$ during the day and $+8^{\circ} \mathrm{C}$ at night. No chilled air was delivered if berry temperature $\left(T_{b}\right)$ was $\leq 10^{\circ} \mathrm{C}$, a temperature found to inhibit photosynthesis in grapevines (Hendrickson et al. 2004). To account for the effects of heat transfer by forced convection, ambient air was delivered to blow clusters at the same rate that heated or cooled air was delivered to damp clusters.

During Period $I, T_{b}$ was estimated by fine-wire thermocouples ( $0.13 \mathrm{~mm}$ diam; Type $\mathrm{T}$ [copper-constantan]) each encapsulated in a 4 to $6 \mathrm{~mm}$ diam bead of silicone. Four junctions were wired in parallel and were positioned between berries along the length of the rachis. During Period II, bare thermocouples (2-mm long junctions; $0.13 \mathrm{~mm}$ diam) were inserted directly under the berry skin and the insertion point was sealed with water-based glue. Air temperature at cordon height $\left(\mathrm{T}_{\mathrm{a}} ; 1.2 \mathrm{~m}\right.$ aboveground) was measured with a shielded, aspirated fine-wire thermocouple. Global irradiance was measured by pyranometer (model 8-48; Eppley Laboratories, Newport, RI), and irradiance in the fruiting zone was measured by $1-\mathrm{m}$ long tube solarimeters $(\mathrm{n}=3$; model TSL; Delta-T Devices, Cambridge, UK) installed parallel to the cordon at $1.2 \mathrm{~m}$ aboveground. Before deployment, tube solarimeters were oriented north-south and their output was normalized to that of the Eppley pyranometer. Sensor signals were scanned every $5 \mathrm{sec}$ and averages recorded every $12 \mathrm{~min}$ by data acquisition system (AM-25T and CR-10X, Campbell Scientific, Logan, UT).

Clusters for Period I experiments were harvested when the first treated cluster reached veraison, defined by a visually detected change in berry skin color. Period II clusters were harvested when a sample of untreated berries reached commercial maturity. Harvested berries were transported on ice and kept under refrigeration before being excised from the rachis (pedicels cut at flare and receptacle left attached), counted, weighed, frozen in liquid nitrogen, and stored at $-80^{\circ} \mathrm{C}$ until analyses.

Chemical analyses. Prior to manual dissection and separation of skin from seed, berries were thawed and mean berry volume (50 or 100 berries) was estimated by $\mathrm{H}_{2} \mathrm{O}$ displacement. The number of colored berries was determined by visual assessment for reporting percent berry coloration at veraison. To estimate total soluble solids concentration, 15 to 20 frozen berries were crushed and incubated at $75^{\circ} \mathrm{C}$ for $1 \mathrm{hr}$ then centrifuged $(3500 \mathrm{~g}$ ) for $10 \mathrm{~min}$, before determination with a portable digital refractometer (WM-7; Atago, Tokyo, Japan). Skin extracts were prepared by macerating lyophilized, whole 
berry skins in an acetone:water solution $(2: 1)$ at $20^{\circ} \mathrm{C}$ for 24 hr under $\mathrm{N}_{2}$ gas. Seed extracts were prepared similarly except that in 2008, $1 \mathrm{~g}$ of dried seed was extracted using $10 \mathrm{~mL}$ solvent. Following removal of acetone, extracts were brought to volume in ultrapure water and stored at $-30^{\circ} \mathrm{C}$ until analysis.

Flavonols, anthocyanins, and proanthocyanidins (PAs) were analyzed by high-performance liquid chromatography (HPLC) (model 1100; Hewlett-Packard, Palo Alto, CA). The instrument was equipped with a diode array detector (DAD) and an external column oven when required (model $\mathrm{CH}-430$; Eppendorf, Westbury, NY). All data were analyzed with Chemstation software (ver. A.08.03; Agilent, Santa Clara, CA). Analysis of monomeric phenolics was performed following a published method (Lamuela-Raventos and Waterhouse 1994). In 2006, aqueous extracts were filtered using a syringe filter (Acrodisc PTFE [13 mm, $0.45 \mu \mathrm{m}$; Pall Corporation, East Hills, NY). In 2007 and 2008, samples were centrifuged at $16,000 \mathrm{~g}$ for $15 \mathrm{~min}$ to remove solids. Quercetin (Sigma Aldrich, St. Louis, MO) and malvidin-3-O-glucoside (Extrasynthèse, Genay, France) were used as quantitative standards for flavonols and anthocyanins, respectively.

Compositional analysis of PAs was carried out following acid-catalyzed cleavage in the presence of phloroglucinol (phloroglucinolysis). Aliquots of aqueous extracts were lyophilized, dissolved in $\mathrm{MeOH}$, and then reacted with phloroglucinol reagent (1:1) according to a previous method (Kennedy and Jones 2001). Following reaction, samples were combined with aqueous sodium acetate and then analyzed immediately by HPLC (Kennedy and Taylor 2003). Individual PA subunits were quantified as described (Kennedy and Jones 2001) using a (+)-catechin quantitative standard (Sigma Aldrich). Proportions of flavan-3-ol subunits are presented as mole percentages to normalize data for molecular mass.

Statistical analyses. The $\mathrm{T}_{\mathrm{b}}$ values were summarized by experimental period and temperature-control treatment in SAS (ver 9.1; SAS Institute, Cary, NC) using the MEANS procedure. Thermal time above a $10^{\circ} \mathrm{C}$ base temperature was computed from 12-min averages of $\mathrm{T}_{\mathrm{b}}$ and is expressed as degree days (DD). Statistical analyses of metabolite and summarized temperature data were performed using StatGraphics Centurion software (Statpoint Technologies, Warrenton, VA). Significant differences within years were determined using one-way ANOVA at $p<0.05$ and means separated using Fisher's LSD. Two-factor ANOVA (treatment and year) was used to determine treatment and year effects across all years of experimentation $(p<0.05)$. Data that were not normally distributed were analyzed using Kruskal-Wallis ANOVA as indicated in individual tables. Stepwise linear regression used backward selection with an entry criterion of $\mathrm{F}>4.0$.

\section{Results}

Berry temperature. Daily mean, maximum, and minimum $T_{b}$ (Figure 1) indicate the effectiveness of temperature control in compressing the DTR. Daily mean temperatures were similar for all treatments; therefore values are shown for ambient only. The daily mean $\mathrm{T}_{\mathrm{b}}$ of blow typically differed by less than $0.5^{\circ} \mathrm{C}$ from that of ambient berries. There was more variation in daily mean $T_{b}$ in 2006 than in either 2007 or 2008 and longer periods of temperatures above $35^{\circ} \mathrm{C}$. Effective temperature control nearly eliminated temperatures $>35^{\circ} \mathrm{C}$ or $<10^{\circ} \mathrm{C}$ for damp berries (Table 1). In both experimental periods and across all years, the DTR for damp clusters was compressed more than those of ambient and blow clusters, which were not different from each other. Preveraison, there was a higher average DTR in 2008 than in either 2006 or 2007 ( $p<0.001$, not shown), but less day-to-day variability in mean temperature. After veraison, the average DTR was higher in $2006(p<0.01)$.

Normalizing DD to the duration of the experiment resulted in lower DD for 2008 than either 2006 or 2007 ( $p<0.05$; data not shown) in Period I. After veraison, more thermal time accumulated in 2006 than 2007. The DD accumulated by berries differed between damp and ambient only in Period I of 2006 (Table 1). Ambient and blow clusters exceeded $25^{\circ} \mathrm{C}$, $30^{\circ} \mathrm{C}$, and $35^{\circ} \mathrm{C}$ for the same amount of time, while damp clusters exceeded $25^{\circ} \mathrm{C}, 30^{\circ} \mathrm{C}$, and $35^{\circ} \mathrm{C}$ for less time in all years, except during Period II of 2007. Consequently, damp clusters were maintained between 20 and $25^{\circ} \mathrm{C}$ for a greater
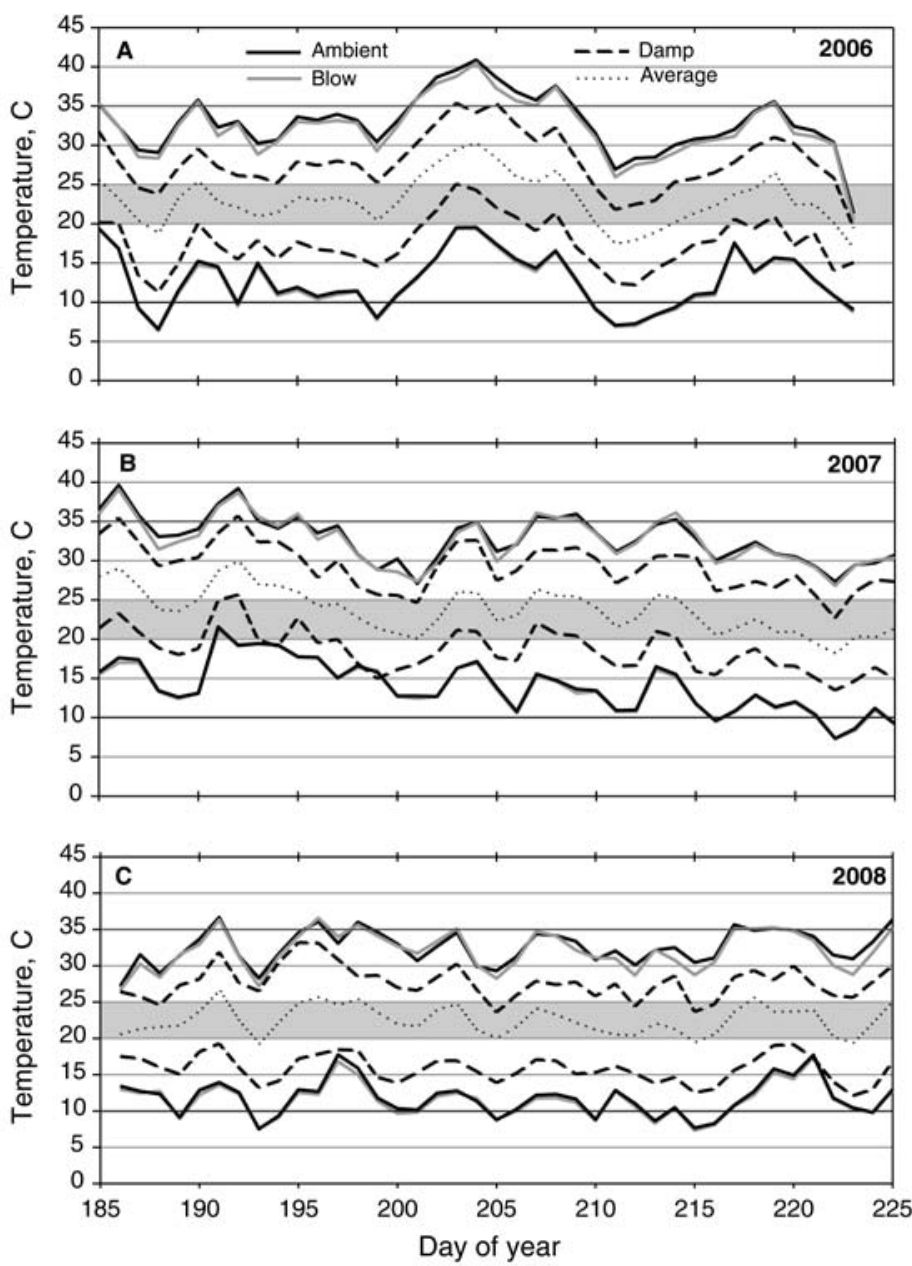

Figure 1 Exemplary data $(n=4)$ showing average daily maximum (three upper traces), ambient daily mean (center trace), and average daily minimum (three lower traces) temperatures during Period I in 2006 (A), 2007 (B), and $2008(C)$, and with theoretical minimum $\left(10^{\circ} \mathrm{C}\right)$, maximum $\left(35^{\circ} \mathrm{C}\right)$, and optimum $\left(20-25^{\circ} \mathrm{C}\right)$ temperatures for berry metabolism indicated. 
proportion of the experiment than were ambient or blow clusters. The timing of exposure to higher temperatures $\left(>35^{\circ} \mathrm{C}\right)$ in ambient and blow berries differed among years (Figure 1). That is noteworthy, as potentially detrimental temperatures would have occurred during slightly different stages of berry development in each year.

Berry size and composition. The compressed DTR of damp resulted in higher berry mass at veraison than ambient or blow in all years (Table 2). Berry volume was proportional to berry mass in all cases $\left(r^{2} \approx 0.97\right.$, data not shown). Larger berries in combination with higher coloration and higher soluble solids content at veraison indicate considerable hastening of berry development by compressing DTR. The mass of skin per berry at the end of Period I was higher in damp berries than in ambient berries in 2006 and 2007. Data from a concurrent experiment showed that the rate of berry development of damp berries was higher than that from equivalent levels of daytime cooling $\left(-8^{\circ} \mathrm{C}\right.$ from ambient) or nighttime heating $\left(+8^{\circ} \mathrm{C}\right.$ from ambient) alone (Cohen et al. 2008). At veraison there were interannual differences in the number of seeds per berry, in the order 2008>2006>2007 ( $p$ $<0.001$, data not shown).

After Period II, there were no differences in berry mass due to treatments (Table 2). Skin dry mass was lower and soluble solids were higher in damp than in ambient in 2007. Interannual differences in soluble solids in ambient berries (2007>2006; $p<0.01)$ may have contributed to differences in treatment effect on other measured variables. Similarly to veraison, there were no differences in number of seeds per berry or seed fresh mass at harvest due to treatments.

Seed proanthocyanidins. At veraison, seed PA content per berry was not significantly affected by treatments (data not shown). Among years, per seed content was highest in ambient berries in $2008(p<0.01)$. Overall, seed PA content $(p<0.01)$ was highest in 2007 , but lowest in that year if expressed per berry, probably because of lower seed numbers per berry. Average polymer size (mean degree of polymerization; mDP) of seed PA was lower in ambient than in damp berries in 2007 and 2008 (Table 3). By veraison, seeds had

Table 2 Berry mass, skin mass per berry, soluble solids, and percent berry coloration at veraison (Period I) and harvest (Period II).

\begin{tabular}{cccccr}
\hline & Treatment & $\begin{array}{c}\text { Berry } \\
\text { mass } \\
(\mathbf{g})\end{array}$ & $\begin{array}{c}\text { Skin } \\
\text { mass } \\
\text { (mg/berry) }\end{array}$ & $\begin{array}{c}\text { Soluble } \\
\text { solids } \\
\text { (Brix) }\end{array}$ & $\begin{array}{c}\text { Colored } \\
\text { berries } \\
(\%)^{\mathrm{a}}\end{array}$ \\
\hline Period I & & & & & \\
$2006^{\mathrm{b}}$ & Ambient & $0.50 \mathrm{a}^{\mathrm{c}}$ & $12.0 \mathrm{a}$ & $6.4 \mathrm{a}$ & $<1.0 \mathrm{a}$ \\
& Blow & $0.52 \mathrm{a}$ & $11.1 \mathrm{a}$ & $6.7 \mathrm{a}$ & $1.0 \mathrm{a}$ \\
2007 & Damp & $0.75 \mathrm{~b}$ & $14.1 \mathrm{~b}$ & $10.7 \mathrm{~b}$ & $32.5 \mathrm{~b}$ \\
& Ambient & $0.69 \mathrm{a}$ & $12.0 \mathrm{a}$ & $8.6 \mathrm{a}$ & $<1.0 \mathrm{a}$ \\
& Blow & $0.60 \mathrm{a}$ & $10.9 \mathrm{a}$ & $7.6 \mathrm{a}$ & $4.0 \mathrm{a}$ \\
2008 & Damp & $0.81 \mathrm{~b}$ & $14.1 \mathrm{~b}$ & $10.8 \mathrm{~b}$ & $40.0 \mathrm{~b}$ \\
& Ambient & $0.63 \mathrm{a}$ & $13.2 \mathrm{nd}$ & $5.8 \mathrm{a}$ & $<1.0 \mathrm{a}$ \\
& Blow & $0.60 \mathrm{a}$ & 11.3 & $6.0 \mathrm{a}$ & $<1.0 \mathrm{a}$ \\
Period IId & Damp & $0.83 \mathrm{~b}$ & 13.9 & $10.0 \mathrm{~b}$ & $36.8 \mathrm{~b}$ \\
& & & & & \\
& Ambient & $0.98 \mathrm{nd}$ & $22.3 \mathrm{nd}$ & $22.2 \mathrm{nd}$ & $\mathrm{na}$ \\
& Blow & 1.01 & 22.6 & 23.2 & $\mathrm{na}$ \\
& Damp & 1.04 & 26.4 & 23.6 & $\mathrm{na}$ \\
& Ambient & $1.07 \mathrm{nd}$ & $25.4 \mathrm{~b}$ & $25.3 \mathrm{a}$ & $\mathrm{na}$ \\
& Blow & 1.02 & $20.6 \mathrm{ab}$ & $25.1 \mathrm{a}$ & $\mathrm{na}$ \\
& Damp & 0.94 & $18.1 \mathrm{a}$ & $26.5 \mathrm{~b}$ & $\mathrm{na}$ \\
\hline
\end{tabular}

aPercent coloration only relevant at veraison; na: not applicable. b2006 data extracted from previous experiment (Cohen et al. 2008). 'Letters denote differences between treatments within year using Fisher's LSD, $p \leq 0.05$; italics denote Kruskal-Wallis ANOVA at $p \leq$ $0.05 ;$ nd $=$ not different.

dPeriod II experiment conducted in 2006 and 2007 only.

Table 1 Treatment duration (days), thermal time summaries (DD), average diurnal temperature range (DTR), and number of hours above indicated temperatures during each experimental period.

\begin{tabular}{|c|c|c|c|c|c|c|c|c|}
\hline \multirow[b]{2}{*}{ Year } & \multirow{2}{*}{$\begin{array}{c}\text { Duration } \\
\text { (days) }\end{array}$} & \multirow[b]{2}{*}{ Treatment } & \multirow[b]{2}{*}{ DD sum ${ }^{\mathrm{a}}$} & \multirow{2}{*}{$\begin{array}{l}\text { DTR } \\
\left({ }^{\circ} \mathrm{C}\right)\end{array}$} & \multicolumn{4}{|c|}{ Hours (n) above indicated temperature } \\
\hline & & & & & $>40^{\circ} \mathrm{C}$ & $>35^{\circ} \mathrm{C}$ & $>30^{\circ} \mathrm{C}$ & $>25^{\circ} \mathrm{C}$ \\
\hline \multicolumn{9}{|l|}{ Period I } \\
\hline \multirow[t]{3}{*}{$2006^{b}$} & 45 & Ambient & $605.2 b^{c}$ & $19.6 \mathrm{~b}$ & $2.7 \mathrm{nd}$ & $58.1 \mathrm{~b}$ & $256.7 \mathrm{~b}$ & $501.0 \mathrm{~b}$ \\
\hline & & Blow & $596.6 \mathrm{~b}$ & $18.9 \mathrm{~b}$ & 1.1 & $46.6 \mathrm{~b}$ & $235.5 \mathrm{~b}$ & $481.1 \mathrm{~b}$ \\
\hline & & Damp & $580.5 \mathrm{a}$ & $10.2 \mathrm{a}$ & 0.0 & $1.9 \mathrm{a}$ & $65.1 \mathrm{a}$ & $356.4 \mathrm{a}$ \\
\hline \multirow[t]{3}{*}{2007} & 44 & Ambient & $595.4 \mathrm{nd}$ & $18.9 \mathrm{~b}$ & $0.6 \mathrm{nd}$ & $36.9 \mathrm{~b}$ & $236.1 \mathrm{~b}$ & $504.6 \mathrm{~b}$ \\
\hline & & Blow & 597.5 & $18.5 \mathrm{~b}$ & 0.0 & $37.2 \mathrm{~b}$ & $235.3 \mathrm{~b}$ & $503.4 \mathrm{~b}$ \\
\hline & & Damp & 592.3 & $10.6 \mathrm{a}$ & 0.0 & $6.1 \mathrm{a}$ & $76.9 \mathrm{a}$ & $382.5 \mathrm{a}$ \\
\hline \multirow[t]{3}{*}{2008} & 46 & Ambient & 589.9 nd & $21.1 \mathrm{~b}$ & $0.5 \mathrm{nd}$ & $38.3 \mathrm{~b}$ & $237.6 \mathrm{~b}$ & $502.6 \mathrm{~b}$ \\
\hline & & Blow & 589.5 & $20.3 \mathrm{~b}$ & 0.0 & $29.1 \mathrm{~b}$ & $226.4 \mathrm{~b}$ & $495.0 \mathrm{~b}$ \\
\hline & & Damp & 566.4 & $11.8 \mathrm{a}$ & 0.9 & $3.5 \mathrm{a}$ & $30.2 \mathrm{a}$ & $317.3 \mathrm{a}$ \\
\hline \multicolumn{9}{|c|}{ Period II } \\
\hline \multirow[t]{3}{*}{2006} & 43 & Ambient & $431.7 \mathrm{nd}$ & $24.1 \mathrm{~b}$ & $4.0 \mathrm{nd}$ & $43.4 \mathrm{~b}$ & $180.9 \mathrm{~b}$ & $310.3 b$ \\
\hline & & Blow & 417.6 & $22.3 \mathrm{~b}$ & 0.8 & $26.0 \mathrm{ab}$ & $156.7 \mathrm{~b}$ & $296.2 b$ \\
\hline & & Damp & 419.2 & $14.4 \mathrm{a}$ & 0.3 & $11.9 \mathrm{a}$ & $57.4 \mathrm{a}$ & $205.4 \mathrm{a}$ \\
\hline \multirow[t]{3}{*}{2007} & 41 & Ambient & 391.0 nd & $21.8 \mathrm{~b}$ & $0.9 \mathrm{nd}$ & $14.6 \mathrm{nd}$ & $108.5 \mathrm{~b}$ & $276.2 \mathrm{c}$ \\
\hline & & Blow & 380.4 & $20.4 \mathrm{~b}$ & 0.6 & 9.4 & $81.0 \mathrm{~b}$ & $257.5 b$ \\
\hline & & Damp & 374.3 & $12.7 \mathrm{a}$ & 0.0 & 0.0 & $5.5 \mathrm{a}$ & $131.7 \mathrm{a}$ \\
\hline
\end{tabular}

${ }^{a}$ Expressed as degree days $\left({ }^{\circ} \mathrm{C}\right)$ above base $10^{\circ} \mathrm{C}$.

b2006 data extracted from previous experiment (Cohen et al. 2008).

'Letters denote differences between treatments within year using Fisher's LSD, $p \leq 0.05$; nd = not different. 
accumulated considerable quantities of flavan-3-ol monomers (data not shown). Total monomer content followed interannual patterns similar to total seed PA content. Treatment differences at veraison were limited to higher monomer contents per seed in damp berries in 2006.

Flavan-3-ol monomer composition in seeds differed among treatments at veraison (Table 3). In 2006, the proportion of $(+)$-catechin $(\mathrm{Cm})$ was highest in damp berries. Proportions of (-)-epicatechin (ECm) were highest in damp berries in 2007 and 2008 and when data were pooled across years $(p<0.001)$. The proportion of (-)-epicatetchin-3-O-gallate (ECGm) was consistently lowest in damp berries in all years. Neither DD alone nor DD combined with DTR was a significant predictor of ECGm $(p=0.1)$. The data indicate that DTR compression results in lower gallate-esterification of seed flavan-3-ol monomers. Average DTR across Period I explained 83.2\% (2006), 51.9\% (2007), and 97.2\% (2008) of variance in proportions of ECGm $(p<0.001)$. Pooling data across years yielded a linear model \%ECGm $=0.0113961+0.00634433 * \mathrm{DTR}(\mathrm{adj}$ $\left.\mathrm{r}^{2}=0.507, \mathrm{SE}=0.0264, p<0.001\right)$.

Relative ranks in PA polymers due to treatment and year were similar to those observed with total PA content at veraison, except that the distribution of terminal subunits showed no influence of temperature. Overall, the proportion of ECGt was highest in 2006, followed by 2007, then $2008(p<0.001)$. The proportion of $(+)$-catechin extension subunits $(\mathrm{Cx})$ was higher in damp berries in 2006 (Table 3); values were highest in 2008 when pooled across years $(p<0.001)$. The proportion of (-)-epicatechin as an extension subunit (ECx) did not differ due to treatment; pooled values were highest in $2007(p<$ 0.001). Contrary to ECGm, the proportion of (-)-epicatechin-
3-O-gallate extension subunits (ECGx) was not different between treatments. Pooled values followed the same pattern as ECGm with respect to year $(2006>2008>2007$; $p<0.001)$.

After Period II, there were no significant treatment effects on seed PAs, either per berry (data not shown) or per seed (Table 3). Per seed PA content was higher in 2007 than in $2006(p<0.001)$, similar to Period I. The content of seed flavan-3-ol monomers was higher in 2007 on both per berry and per seed basis $(p<0.01)$, but no treatment effect was observed. There were no significant differences in seed PA $\mathrm{mDP}$ due to treatment; average mDP was higher in 2006 than in 2007 ( $p<0.001)$. The proportion of ECGm in damp berries was lower than that in ambient berries in 2006; ECGm proportions were higher in 2006 than in $2007(p<0.001)$.

Consistent with total PAs, flavan-3-ol monomers, and outcomes from Period I, there were no differences in total polymeric seed PAs between treatments after Period II, although overall contents were higher in 2007 (data not shown, $p<0.001)$. The distribution of terminal subunits showed no effect of treatment; interannual differences were consistent with those for monomer and extension subunits (Table 3). The proportions of $\mathrm{Cx}$ and $\mathrm{ECx}$ were higher in 2007, while that of ECGx was lower $(p<0.01)$.

Skin proanthocyanidins. Treatments had no effect on total skin PA content per berry in either period (Table 4). Damp resulted in the lowest PA content per unit berry fresh mass when data were pooled across years (data not shown, $p<0.01)$. The mDP was lower in damp berries in 2006 and when data were pooled across years $(p<0.01)$. There were no significant differences between treatments in content of flavan-3-ol monomers or terminal subunits in berry skins at

Table 3 Total proanthocyanidin (PA) content, mean degree of polymerization (mDP), and subunit composition (mole percentage) as a portion of total in seed PA at veraison (Period I) and harvest (Period II).

\begin{tabular}{|c|c|c|c|c|c|c|c|c|c|c|c|c|c|}
\hline & \multirow[b]{3}{*}{ Treatment } & \multirow{3}{*}{$\begin{array}{c}\text { Total PA } \\
\text { (mg/seed) }\end{array}$} & \multirow[b]{3}{*}{$\mathrm{mDP}$} & \multicolumn{10}{|c|}{ PA composition $^{a}$} \\
\hline & & & & \multicolumn{3}{|c|}{ Monomers (\%) } & \multicolumn{3}{|c|}{ Terminal units (\%) } & \multicolumn{4}{|c|}{ Extension units (\%) } \\
\hline & & & & $\mathrm{Cm}$ & $\mathrm{ECm}$ & ECGm & Ct & ECt & ECGt & $\mathbf{C x}$ & ECx & ECGx & EGCx \\
\hline \multicolumn{14}{|c|}{ Period I } \\
\hline \multirow[t]{3}{*}{$2006^{b}$} & Ambient & $2.38 \mathrm{nd}^{\mathrm{c}}$ & $11.7 \mathrm{nd}$ & $55.1 \mathrm{a}$ & 27.9nd & $17.0 \mathrm{~b}$ & 18.9nd & $3.4 \mathrm{nd}$ & 77.7nd & $6.9 a$ & $70.1 \mathrm{nd}$ & 21.5nd & $1.5 \mathrm{nd}$ \\
\hline & Blow & 2.46 & 10.8 & $55.8 a$ & 28.3 & $15.8 b$ & 20.9 & 7.6 & 71.4 & $7.2 \mathrm{a}$ & 70.9 & 20.3 & 1.5 \\
\hline & Damp & 2.73 & 13.7 & $59.8 b$ & 30.1 & $10.1 \mathrm{a}$ & 8.3 & 4.0 & 87.7 & $9.1 b$ & 68.4 & 20.6 & 1.9 \\
\hline \multirow[t]{3}{*}{2007} & Ambient & $3.21 \mathrm{nd}$ & $8.9 a$ & 58.0nd & $32.8 a$ & $9.2 b$ & $22.4 \mathrm{nd}$ & 19.2nd & 58.5nd & 8.0nd & $77.2 n d$ & 13.4nd & 1.3nd \\
\hline & Blow & 3.01 & $9.4 a$ & 59.0 & $30.7 a$ & $10.2 b$ & 21.7 & 15.6 & 62.8 & 8.4 & 77.0 & 13.3 & 1.4 \\
\hline & Damp & 2.75 & $10.8 b$ & 56.0 & $36.9 b$ & 7.1a & 16.5 & 17.8 & 65.7 & 8.7 & 76.7 & 13.3 & 1.3 \\
\hline \multirow[t]{3}{*}{2008} & Ambient & $2.51 \mathrm{nd}$ & $6.8 \mathrm{a}$ & 53.7nd & $31.4 a$ & $14.9 \mathrm{~b}$ & $40.2 \mathrm{nd}$ & $17.2 b$ & $42.5 a$ & 9.6nd & 73.3nd & $14.6 a$ & 2.6nd \\
\hline & Blow & 2.14 & $9.0 b$ & 53.9 & $32.1 \mathrm{a}$ & $14.0 \mathrm{~b}$ & 38.0 & $7.0 a$ & $54.9 \mathrm{~b}$ & 9.9 & 71.9 & $15.5 b$ & 2.7 \\
\hline & Damp & 1.94 & $7.9 a b$ & 51.7 & $41.3 b$ & 7.0a & 42.2 & $16.0 \mathrm{~b}$ & $41.8 \mathrm{a}$ & 10.5 & 71.6 & $15.9 b$ & 2.0 \\
\hline \multicolumn{14}{|c|}{ Period II } \\
\hline \multirow[t]{3}{*}{2006} & Ambient & $1.31 \mathrm{nd}$ & 9.5nd & $52.5 \mathrm{nd}$ & $37.8 \mathrm{nd}$ & $9.7 b$ & $26.5 n d$ & $17.8 \mathrm{nd}$ & 55.7nd & 8.0nd & 69.6nd & 22.3nd & $0.2 a$ \\
\hline & Blow & 1.23 & 9.9 & 53.8 & 38.1 & $8.1 a b$ & 20.3 & 19.8 & 59.8 & 7.4 & 71.0 & 21.2 & $0.4 a$ \\
\hline & Damp & 1.24 & 9.8 & 52.7 & 40.2 & $7.1 \mathrm{a}$ & 25.1 & 18.1 & 56.8 & 7.6 & 68.0 & 21.5 & $2.9 b$ \\
\hline \multirow[t]{3}{*}{2007} & Ambient & $2.11 \mathrm{nd}$ & $6.5 a b$ & $55.7 \mathrm{nd}$ & $38.1 \mathrm{nd}$ & $6.2 \mathrm{nd}$ & $36.5 \mathrm{nd}$ & $25.9 a$ & $37.5 \mathrm{nd}$ & $8.8 n d$ & 76.0nd & 13.5nd & $1.6 \mathrm{nd}$ \\
\hline & Blow & 1.87 & $6.4 \mathrm{a}$ & 56.1 & 38.2 & 5.8 & 35.2 & $28.5 b$ & 36.4 & 8.5 & 76.8 & 12.9 & 1.8 \\
\hline & Damp & 1.77 & $6.9 \mathrm{~b}$ & 51.6 & 41.8 & 6.6 & 37.1 & $24.7 a$ & 38.3 & 9.1 & 75.6 & 13.8 & 1.5 \\
\hline
\end{tabular}

aAbbreviations: C, (+)-catechin; EC, (-)-epicatechin; ECG, (-)-epicatechin-3-O-gallate; EGC, (-)-epigallocatechin; m, t, x: monomer, terminal, and extension units, respectively.

b2006 data extracted from previous experiment (Cohen et al. 2008).

'Letters denote differences between treatments within year using Fisher's LSD, $p \leq 0.05$; italics denote Kruskal-Wallis ANOVA at $p \leq 0.05$; nd $=$ not different. 
the termination of either Period I or Period II. No treatment effect was observed for Ct, ECt, or ECGt proportions after Period I. The proportion of $\mathrm{Ct}$ was lowest in 2006 when those of ECt and ECGt were highest $(p<0.01)$. By contrast, the proportion of $\mathrm{Ct}$ was lower in 2007 than 2006 at the end of Period II $(p<0.01)$, due to the higher contribution of ECGt to the total pool that year. In general, skin PA extension subunit content was highest in $2008(p<0.001)$ as with total PA content. Proportions of epigallocatechin (EGCx) and ECGx during Period I were highest in 2007 when proportions of $\mathrm{ECx}$ were lowest $(p<0.001)$; otherwise no treatment differences were observed for PA extension subunit content or composition at veraison.

During Period II, treatments had little effect on total PAs in berry skins (data not shown), with no differences detected at harvest (Table 4). Overall content of skin PAs were higher in 2006, both per berry and by unit skin mass $(p<0.05)$. There were no differences in PA mDP between treatments or years. The distribution of extension subunits was not affected by treatment in 2006 (Table 4); total extension subunits were higher in ambient berries in 2007. In that year the proportion of Cx was higher and that of ECGx was lower in damp than in ambient berries, but these subunits represent less than 3\% of total extension units.

Skin anthocyanins and flavonols. From visual inspection of color, damp berries consistently accumulated anthocyanins earlier than other treatments. At veraison, more berries per damp cluster expressed color than per ambient cluster (Table 2). Analysis of anthocyanins confirmed this outcome: content was undetectable or very low in ambient and blow berries and at $\geq 10 \mu \mathrm{g}$ per berry in damp berries (data not shown).
The compositional variation in anthocyanins was low early in development (i.e., up to veraison) due to a lack of acylation, which increased rapidly after veraison.

At the end of Period II, there were contrasting treatment differences by year: there was no difference between treatments in total anthocyanins in 2006, but anthocyanin concentrations were lower in damp berries in 2007 (Table 5), reflecting the outcome found in seed and skin PAs and flavonols. Normalizing the data by berry mass eliminated all differences in anthocyanins. In all circumstances the proportion of di-substituted anthocyanins was highest in damp berries at the end of Period II. The overall proportion of di-substituted anthocyanins was considerably higher in 2007; differences were evident in higher contents of cyanidin- and peonidin-glucosides

\begin{tabular}{|c|c|c|c|c|c|c|}
\hline & \multicolumn{6}{|c|}{$\begin{array}{c}\text { Table } 5 \text { Total anthocyanin content and composition } \\
\text { (mass percent) of skins at harvest. }\end{array}$} \\
\hline & \multirow[b]{2}{*}{ Treatment } & \multicolumn{5}{|c|}{ Anthocyanin $^{\mathrm{a}}$} \\
\hline & & $\begin{array}{c}\mu \mathrm{g} / \\
\text { berry }\end{array}$ & $\begin{array}{c}\mathrm{Di} \\
(\%)\end{array}$ & $\begin{array}{l}\text { Tri } \\
(\%)\end{array}$ & $\begin{array}{c}\text { Acetyl } \\
(\%)\end{array}$ & $\begin{array}{c}\text { Coum } \\
(\%)\end{array}$ \\
\hline \multirow[t]{3}{*}{$2006^{b}$} & Ambient & $900.5 \mathrm{nd}^{\mathrm{c}}$ & $11.6 \mathrm{a}$ & $88.4 \mathrm{~b}$ & $17.4 \mathrm{~b}$ & $9.8 \mathrm{~b}$ \\
\hline & Blow & 996.6 & $13.6 \mathrm{a}$ & $86.4 \mathrm{~b}$ & $18.5 \mathrm{~b}$ & $6.6 \mathrm{ab}$ \\
\hline & Damp & 1078.6 & $21.3 \mathrm{~b}$ & $78.7 \mathrm{a}$ & $13.0 \mathrm{a}$ & $4.3 \mathrm{a}$ \\
\hline \multirow[t]{3}{*}{2007} & Ambient & $928.5 \mathrm{~b}$ & $30.1 \mathrm{a}$ & $69.9 \mathrm{~b}$ & $14.6 \mathrm{~b}$ & $4.7 \mathrm{c}$ \\
\hline & Blow & $888.1 \mathrm{~b}$ & $29.8 \mathrm{a}$ & $70.2 \mathrm{~b}$ & $14.6 \mathrm{~b}$ & $3.7 \mathrm{~b}$ \\
\hline & Damp & $693.3 \mathrm{a}$ & $44.1 \mathrm{~b}$ & $55.9 \mathrm{a}$ & $10.5 \mathrm{a}$ & $2.1 \mathrm{a}$ \\
\hline
\end{tabular}

aExpressed in malvidin-3-O-glucoside equivalence ( $\mu$ g per berry) of di-substituted, tri-substituted, acetyl-glucosides, and coumaroylglucosides (Di, Tri, Acetyl, and Coum, respectively).

b2006 data extracted from previous experiment (Cohen et al. 2008).

'Letters denote differences between treatments within year using Fisher's LSD, $p \leq 0.05 ; \mathrm{nd}=$ not different.

Table 4 Total proanthocyanidin (PA) content, mean degree of polymerization (mDP), and subunit compositions (mole percentage) as a portion of total terminal and extension units in skin PAs at veraison (Period I) and harvest (Period II).

\begin{tabular}{|c|c|c|c|c|c|c|c|c|c|c|}
\hline & \multirow[b]{3}{*}{ Treatment } & \multirow{3}{*}{$\begin{array}{l}\text { Total PAs } \\
\text { (mg/berry) }\end{array}$} & \multirow[b]{3}{*}{ mDP } & \multicolumn{7}{|c|}{ PA composition ${ }^{a}$} \\
\hline & & & & \multicolumn{3}{|c|}{ Terminal units (\%) } & \multicolumn{4}{|c|}{ Extension units (\%) } \\
\hline & & & & $\mathbf{C t}$ & ECt & ECGt & $\mathbf{C x}$ & ECx & ECGX & EGCx \\
\hline \multicolumn{11}{|l|}{ Period I } \\
\hline \multirow[t]{3}{*}{$2006^{b}$} & Ambient & $1.16 \mathrm{nd}^{\mathrm{c}}$ & $26.0 \mathrm{~b}$ & $78.2 \mathrm{nd}$ & $14.5 \mathrm{nd}$ & 7.3nd & $1.5 \mathrm{nd}$ & 53.6nd & $1.9 n d$ & 43.0nd \\
\hline & Blow & 1.14 & $25.4 b$ & 81.1 & 11.6 & 7.3 & 1.5 & 53.0 & 1.7 & 43.8 \\
\hline & Damp & 1.04 & $20.6 a$ & 84.6 & 10.1 & 5.3 & 1.5 & 52.6 & 1.6 & 44.3 \\
\hline \multirow[t]{3}{*}{2007} & Ambient & $0.96 n d$ & $24.9 a b$ & 90.0nd & 8.8nd & $1.2 \mathrm{nd}$ & $1.3 b$ & $47.4 \mathrm{nd}$ & $2.2 \mathrm{nd}$ & $49.2 n d$ \\
\hline & Blow & 1.18 & $29.0 b$ & 88.1 & 10.2 & 1.7 & $1.1 \mathrm{a}$ & 44.5 & 1.9 & 52.4 \\
\hline & Damp & 1.03 & $22.4 a$ & 91.4 & 7.1 & 1.5 & $1.2 a b$ & 46.8 & 2.1 & 49.9 \\
\hline \multirow[t]{3}{*}{2008} & Ambient & $1.41 \mathrm{nd}$ & $27.1 \mathrm{nd}$ & 89.3nd & $8.6 n d$ & $2.1 \mathrm{nd}$ & $1.4 \mathrm{nd}$ & $54.4 \mathrm{nd}$ & $1.6 \mathrm{nd}$ & $42.5 \mathrm{nd}$ \\
\hline & Blow & 1.49 & 28.0 & 88.2 & 9.9 & 1.9 & 1.4 & 52.4 & 1.5 & 44.8 \\
\hline & Damp & 1.77 & 27.5 & 90.7 & 7.5 & 1.8 & 1.3 & 52.4 & 1.6 & 44.7 \\
\hline \multicolumn{11}{|c|}{ Period II } \\
\hline \multirow[t]{3}{*}{2006} & Ambient & $1.34 \mathrm{nd}$ & 26.2nd & 89nd & $11 \mathrm{nd}$ & $0.0 n d$ & $1.4 \mathrm{nd}$ & $54.4 \mathrm{nd}$ & $1.4 \mathrm{nd}$ & 42.8nd \\
\hline & Blow & 1.10 & 26.4 & 85.1 & 11.8 & 3.2 & 1.5 & 53.5 & 1.3 & 43.6 \\
\hline & Damp & 1.31 & 24.5 & 84.6 & 13.0 & 2.4 & 1.4 & 52.8 & 1.2 & 44.6 \\
\hline \multirow[t]{3}{*}{2007} & Ambient & 1.17nd & 26.3nd & $76.5 a b$ & $16.6 \mathrm{nd}$ & $6.8 \mathrm{nd}$ & $1.4 \mathrm{a}$ & 47.6nd & $2.0 \mathrm{a}$ & 49nd \\
\hline & Blow & 0.94 & 23.0 & $72.3 a$ & 20.9 & 6.9 & $1.5 \mathrm{a}$ & 49.2 & $2.6 b$ & 46.7 \\
\hline & Damp & 0.90 & 23.4 & $77.8 \mathrm{~b}$ & 15.5 & 6.7 & $1.7 \mathrm{~b}$ & 49.9 & $2.7 \mathrm{~b}$ & 45.6 \\
\hline
\end{tabular}

${ }^{a}$ Abbreviations: C, (+)-catechin; EC, (-)-epicatechin; ECG, (-)-epicatechin-3-O-gallate; EGC, (-)-epigallocatechin; $t$ and x, total terminal and extension units, respectively.

b2006 data extracted from previous experiment (Cohen et al. 2008).

'Letters denote differences between treatments within year using Fisher's LSD, $p \leq 0.05$; nd = not different. 
concomitant with lower malvidin-3-O-glucoside and acylated derivatives (data not shown). The proportion of anthocyanins in the form of acetyl-glucosides was lower in damp berries in both years and lowest in 2007 when data were pooled ( $p$ $<0.001)$. Similarly, coumaroyl-glucosides were also lower in damp than ambient, and higher in 2006 than $2007(p<$ $0.001)$. In general, damp resulted in lower proportions of trisubstituted anthocyanins or in acetyl- and coumaroyl-glucoside forms, which agrees with work conducted elsewhere related to reduced daytime temperature and in cool years in Merlot and Shiraz berries (Downey et al. 2004, Tarara et al. 2008).

By year, treatments appeared to have no effect on flavonol content per berry at veraison or harvest (Table 6). When Period I data were pooled across years, ambient berries had lower total flavonol content $(p<0.05)$. Across years on a mass basis, which shows the effect of berry size, blow berries had the highest content (data not shown, $p<0.01$ ). Similar to anthocyanins, chemical diversity in flavonols was more limited during Period I. Initially, quercetin derivatives were dominant; hence a higher proportion of di-hydroxylated (di-OH) flavonols in ambient and blow berries. Damp berries accumulated higher proportions of mono-hydroxylated (mono-OH) flavonols by veraison only in 2006. The proportion of di-OH flavonols at harvest was higher in damp berries in 2007 and when data were pooled across years $(p<0.01)$. By year, the proportion in the di-OH form was highest in $2007(p<0.001)$, similar to that of anthocyanins and opposite that of skin PAs.

\section{Discussion}

The DTR of field-grown grape berries was compressed by delivery of cold air during the day and warm air at night.

Table 6 Total flavonol content and composition (mass percent) of skins at veraison (Period I) and harvest (Period II).

\begin{tabular}{ccllll}
\hline & & \multicolumn{4}{c}{ Flavonol $^{\mathrm{a}}$} \\
\cline { 3 - 6 } & Treatment & $\begin{array}{c}\boldsymbol{\mu} \mathbf{g} / \\
\text { berry }\end{array}$ & $\begin{array}{c}\text { Mono } \\
(\%)\end{array}$ & $\begin{array}{c}\text { Di } \\
(\%)\end{array}$ & $\begin{array}{c}\text { Tri } \\
(\%)\end{array}$ \\
\hline Period I & & & & & \\
$2006^{\mathrm{b}}$ & Ambient & $19.8 \mathrm{nd}^{\mathrm{c}}$ & $3.2 \mathrm{a}$ & $96.0 \mathrm{~b}$ & $0.9 \mathrm{nd}$ \\
& Blow & 22.4 & $3.3 \mathrm{a}$ & $95.3 \mathrm{~b}$ & 1.4 \\
& Damp & 21.4 & $4.6 \mathrm{~b}$ & $94.1 \mathrm{a}$ & 1.3 \\
2007 & Ambient & $27.1 \mathrm{nd}$ & $3.4 \mathrm{ab}$ & $95.0 \mathrm{~b}$ & $1.6 \mathrm{nd}$ \\
& Blow & 39.0 & $2.9 \mathrm{a}$ & $95.5 \mathrm{~b}$ & 1.6 \\
2008 & Damp & 36.8 & $4.1 \mathrm{~b}$ & $93.7 \mathrm{a}$ & 2.2 \\
& Ambient & $32.4 \mathrm{nd}$ & $1.9 \mathrm{nd}$ & $96.5 \mathrm{nd}$ & $1.6 \mathrm{nd}$ \\
& Blow & 39.1 & 1.7 & 97.0 & 1.3 \\
Period II & Damp & 44.4 & 2.0 & 95.8 & 2.2 \\
& & & & & \\
& Ambient & $78.3 \mathrm{nd}$ & $4.6 \mathrm{nd}$ & $67.5 \mathrm{nd}$ & $27.8 \mathrm{nd}$ \\
& Blow & 66.5 & 3.9 & 63.7 & 32.4 \\
& Damp & 73.1 & 3.7 & 72.6 & 23.8 \\
& Ambient & $71.4 \mathrm{nd}$ & $5.7 \mathrm{nd}$ & $77.1 \mathrm{a}$ & $17.3 \mathrm{~b}$ \\
& Blow & 66.2 & 6.5 & $77.4 \mathrm{a}$ & $16.1 \mathrm{~b}$ \\
& Damp & 47.2 & 5.3 & $82.3 \mathrm{~b}$ & $12.3 \mathrm{a}$ \\
\hline
\end{tabular}

${ }^{a}$ Expressed in quercetin equivalence ( $\mu$ g per berry) of mono-, di-, and tri-hydroxylated flavonols (Mono, Di, and Tri, respectively). b2006 data extracted from previous experiment (Cohen et al. 2008). 'Letters denote differences between treatments within year using Fisher's LSD, $p \leq 0.05$; nd $=$ not different.
These are the first such data to be collected outside controlled environments (Kobayashi et al. 1967, Kliewer and Torres 1972, Kliewer 1973). The treatments altered the duration to which berries were exposed to purported "optimum" tissue temperatures, that is, $\sim 20$ to $25^{\circ} \mathrm{C}$ with respect to photosynthesis and primary metabolism (Kobayashi et al. 1967, Buttrose and Hale 1973). High $\left(\geq 35^{\circ} \mathrm{C}\right)$ and low $\left(\leq 10^{\circ} \mathrm{C}\right)$ air temperatures have been shown to alter berry development and accumulation of sugars, acids, and anthocyanins in grapes; however, responses can be cultivar dependent and vary temporally (Buttrose et al. 1971, Kliewer 1973, Mori et al. 2007, Tarara et al. 2008).

In this study DTR compression hastened berry development, as evident in greater berry mass and larger volume, skin coloration, higher skin weight per berry, and higher soluble solids content at veraison. While it is unclear what magnitude of DTR compression is required to achieve an effect, DTR compression of one-half the magnitude described in this study showed similar results concerning morphology at veraison (Cohen et al. 2008). The data suggest that compressing the DTR of berries grown in areas with a short ripening period could be an effective way to accelerate berry development.

Compressing DTRs resulted in a decrease in ECGm in seeds, likely driven by lower day temperatures (Cohen et al. 2008). That the proportion of ECG as extension and terminal subunits was not affected by DTR suggests that the mechanisms regulating monomeric and polymeric flavan-3-ols in grape seeds are independent. In other work (Cortell and Kennedy 2006), exposure to sunlight resulted in a decrease in ECGx and ECGt in Pinot noir seeds, although ECG was not reported as a monomeric subunit. Research with tea (Camelia sinensis L.) did show lower levels of gallate esterification of flavan-3-ols associated with leaves harvested during cooler months (Yao et al. 2005).

The overall reduction in seed PAs between veraison and harvest is likely related to oxidation, observable by browning of the seed coat leading to an inability to extract and quantify the PAs (Kennedy et al. 2002). Differences due to DTR were most evident as lower proportions of ECG monomeric and terminal subunits between samples collected at veraison and at harvest in 2006 and 2007. That may reflect changes due to seed maturation, development of the seed coat, and differences in rate of polymerization attributed to flavanol galloylation, demonstrated elsewhere in model solutions (Cheynier and Ricardo-da-Silva 1991). Although research with purified PAs suggests that those originating from seed will affect astringency and may be coarse or bitter, application to wine production and quality remains uncertain (Gambuti et al. 2006). Seed additions during wine production have resulted in improvements in wine color and potential aroma character (Lee et al. 2008).

Accumulation of total skin flavonols at veraison did not appear to be affected by DTR in any single year, when expressed per berry. Previous work has demonstrated the effect of solar radiation exposure on flavonol accumulation in grapes (Downey et al. 2004, Tarara et al. 2008). In the current study, 
differences in flavonol contents were limited to partitioning based on flavonoid B-ring hydroxylation, with compressed DTRs resulting in higher proportions of di-OH flavonols at harvest.

The data presented here confirm that the regulation of grape flavonoids differs by stage of berry development. Shifts in flavonoid partitioning due to compressed DTRs were different at veraison and at commercial maturity, which may reflect differences associated with various MYB-type regulatory genes expressed throughout berry development and differences in the reactivity or localization of metabolites (Czemmel et al. 2009, Terrier et al. 2009). Unlike anthocyanins, PAs are subject to polymerization and, therefore, compositional differences may be the result of subunit condensation and associated differences in extractability, which affects downstream analysis. Differences in the chemical structure of flavonoids directly affect their reactivity or stability, making our understanding of metabolite partitioning and modifications important for wine production.

\section{Conclusion}

Results suggest that typical vintage variability is more likely due to the timing of events such as high or low temperatures than to an integrated seasonal value. Compressing the DTR affected the rate of berry development before veraison but had little influence on accumulation of PAs in berry skins or seeds. Flavonol and anthocyanin compositions favored di-substitution with compressed DTRs, while total content was not consistently affected. Additional work concerning the effect of transient temperature exposure is necessary to determine the existence of sensitive developmental stages corresponding to various metabolites.

\section{Literature Cited}

Amerine, M.A., and A.J. Winkler. 1944. Composition and quality of musts and wines of California grapes. Hilgardia 15:493-673.

Boulton, R. 2001. The copigmentation of anthocyanins and its role in the color of red wine: A critical review. Am. J. Enol. Vitic. 52:67-87.

Buttrose, M.S., and C.R. Hale. 1973. Effect of temperature on development of grapevine inflorescence after bud burst. Am. J. Enol. Vitic. 24:14-16.

Buttrose, M.S., C.R. Hale, and M.W. Kliewer. 1971. Effect of temperature on composition of 'Cabernet Sauvignon' berries. Am. J. Enol. Vitic. 22:71-75.

Cheynier, V., and J.M. Ricardo-da-Silva. 1991. Oxidation of grape procyanidins in model solutions containing trans-caffeoyltartaric acid and polyphenol oxidase. J. Agric. Food Chem. 39:1047-1049.

Cohen, S.D., J.M. Tarara, and J.A. Kennedy. 2008. Assessing the impact of temperature on grape phenolic metabolism. Anal. Chim. Acta 621:57-67.

Coombe, B.G. 1995. Growth stages of the grapevine: Adoption of a system for identifying grapevine growth stages. Aust. J. Grape Wine Res. 1:104-110.

Cortell, J.M., and J.A. Kennedy. 2006. Effect of shading on accumulation of flavonoid compounds in (Vitis vinifera L.) Pinot noir fruit and extraction in a model system. J. Agric. Food Chem. 54:8510-8520.

Czemmel, S., R. Stracke, B. Weisshaar, N. Cordon, N.N. Harris, A.R. Walker, S.P. Robinson, and J. Bogs. 2009. The grapevine R2R3MYB transcription factor $V v M Y B F 1$ regulates flavonol synthesis in developing grape berries. Plant Physiol. 151:1513-1530.
Downey, M.O., J.S. Harvey, and S.P. Robinson. 2003a. Analysis of tannins in seeds and skins of Shiraz grapes throughout berry development. Aust. J. Grape Wine Res. 9:15-27.

Downey, M.O., J.S. Harvey, and S.P. Robinson. 2003b. Synthesis of flavonols and expression of flavonol synthase genes in the developing grape berries of Shiraz and Chardonnay (Vitis vinifera L.). Aust. J. Grape Wine Res. 9:110-121.

Downey, M.O., J.S. Harvey, and S.P. Robinson. 2004. The effect of bunch shading on berry development and flavonoid accumulation in Shiraz grapes. Aust. J. Grape Wine Res. 10:55-73.

Gambuti, A., A. Rinaldi, R. Pessina, and L. Moio. 2006. Evaluation of Aglianico grape skin and seed polyphenol astringency by SDSPAGE electrophoresis of salivary proteins after the binding reaction. Food Chem. 97:614-620.

Hendrickson, L., M.C. Ball, J.T. Wood, W.S. Chow, and R.T. Furbank. 2004. Low temperature effects on photosynthesis and growth of grapevine. Plant Cell Environ. 27:795-809.

Kennedy, J.A., and G.P. Jones. 2001. Analysis of proanthocyanidin cleavage products following acid-catalysis in the presence of excess phloroglucinol. J. Agric. Food Chem. 49:1740-1746.

Kennedy, J.A., and A.W. Taylor. 2003. Analysis of proanthocyanidins by high-performance gel permeation chromatography. J. Chromatogr., A 995:99-107.

Kennedy, J.A., M.A. Matthews, and A.L. Waterhouse. 2002. Effect of maturity and vine water status on grape skin and wine flavonoids. Am. J. Enol. Vitic. 53:268-274.

Kliewer, W.M. 1964. Influence of environment on metabolism of organic acids and carbohydrates in Vitis vinifera. I. Temperature. Plant Physiol. 39:869-880.

Kliewer, W.M. 1965. Changes in the concentration of malates, tartrates, and total free acids in flowers and berries of Vitis vinifera. Am. J. Enol. Vitic. 16:92-100.

Kliewer, W.M. 1973. Berry composition of Vitis vinifera cultivars as influenced by photo- and nycto-temperatures during maturation. J. Am. Soc. Hort. Sci. 98:153-159.

Kliewer, W.M. 1977. Influence of temperature, solar radiation and nitrogen on coloration and composition of Emperor grapes. Am. J. Enol. Vitic. 28:96-103.

Kliewer, W.M., and R.E. Torres. 1972. Effect of controlled day and night temperatures on grape coloration. Am. J. Enol. Vitic. 23:71-77.

Kobayashi, A., T. Fukushima, N. Nu, and K. Harada. 1967. Studies on the thermal conditions of grapes. VI. Effects of day and night temperatures on yield and quality of Delaware grapes. J. Jap. Soc. Hort. Sci. 36:1-7.

Koyama, K., and N. Goto-Yamamoto. 2008. Bunch shading during different developmental stages affects the phenolic biosynthesis in berry skins of 'Cabernet Sauvignon' grapes. J. Am. Soc. Hort. Sci. 133:743-753.

Lamuela-Raventós, R.M., and A.L. Waterhouse. 1994. A direct HPLC separation of wine phenolics. Am. J. Enol. Vitic. 45:1-5.

Lee, J.M., J.A. Kennedy, C. Devlin, M. Redhead, and C. Rennaker. 2008. Effect of early seed removal during fermentation on proanthocyanidin extraction in red wine: A commercial production example. Food Chem. 107:1270-1273.

Mori, K., N. Goto-Yamamoto, M. Kitayama, and K. Hashizume. 2007. Loss of anthocyanins in red-wine grape under high temperature. J. Exp. Bot. 58:1935-1945.

Mori, K., S. Sugaya, and H. Gemma. 2005. Decreased anthocyanin biosynthesis in grape berries grown under elevated night temperature condition. Sci. Hort. 105:319-330.

Pirie, A.J.G., and M.G. Mullins. 1980. Concentration of phenolics in the skin of grape berries during fruit development and ripening. Am. J. Enol. Vitic. 31:34-36. 
Smart, R.E., and T.R. Sinclair. 1976. Solar heating of grape berries and other spherical fruits. Agric. Meteor. 17:241-259.

Spayd, S.E., J.M. Tarara, D.L. Mee, and J.C. Ferguson. 2002. Separation of sunlight and temperature effects on the composition of Vitis vinifera cv. Merlot berries. Am. J. Enol. Vitic. 53:171-182.

Tarara, J.M., J.C. Ferguson, and S.E. Spayd. 2000. A chamber-free method of heating and cooling grape clusters in the vineyard. Am. J. Enol. Vitic. 51:182-188.

Tarara, J.M., J. Lee, S.E. Spayd, and C.F. Scagel. 2008. Berry temperature and solar radiation alter acylation, proportion, and concentration of anthocyanin in Merlot grapes. Am. J. Enol. Vitic. 59:235-247.
Terrier, N., L. Torregrosa, A. Ageorges, S. Vialet, C. Verries, V. Cheynier, and C. Romieu. 2009. Ectopic expression of $V v M y b P A 2$ promotes proanthocyanidin biosynthesis in grapevine and suggests additional targets in the pathway. Plant Physiol. 149:1028-1041.

Yamane, T., S.T. Jeong, N. Goto-Yamamoto, Y. Koshita, and S. Kobayashi. 2006. Effects of temperature on anthocyanin biosynthesis in grape berry skins. Am. J. Enol. Vitic. 57:54-59.

Yao, L.H., N. Caffin, B. D’Arcy, Y.M. Jiang, J. Shi, R. Singanusong, X. Liu, N. Datta, Y. Kakuda, and Y. Xu. 2005. Seasonal variations of phenolic compounds in Australia-grown tea (Camellia sinensis). J. Agric. Food Chem. 53:6477-6483. 